\title{
The magnitude of termites to the future of kimberlite exploration in Botswana
}

\author{
Leon R.M. Daniels, Tshireletso A. Dira and Onesimo Kufandikamwe \\ Pangolin Diamonds (Pty) Limited, Tatitown, Botswana \\ ldaniels@pangolindiamonds.com,tdira@pangolindiamonds.com,okufandikamwe@pangolindiamonds.com
}

\section{Introduction}

The majority of the diamond mines in Botswana (Orapa, Jwaneng, Letlhakane, Damsthaa, Lerala and BK11) were discovered as a direct consequence of soil sampling for indicator minerals such as garnet and picroilmenite. Over the past sixty years the application of soil sampling for indicator minerals as a primary exploration tool has diminished while aeromagnetic surveys have increased in popularity. The rate of kimberlite discovery in Botswana over the past fifteen years has declined significantly. The obvious magnetic kimberlites have been discovered. The future of new kimberlite discoveries, mainly poorly magnetic to non-magnetic, is once again dependent on soil sampling for kimberlite indicator minerals. The only mechanism to transport indicators from source to surface through the Kalahari Formation overburden is through termite bioturbation.

\section{Soil Sampling History in Botswana}

Initial soil sampling programmes conducted by De Beers and Central African Selection Trust (CAST) in Botswana (then Bechuanaland) during the mid to late 1950's were confined to stream sediments in areas where drainage was developed. Concentrates were generated using gold pans. This method was quite ineffective and possibly resulted in Jwaneng being missed in a soil sampling programme conducted in 1962 (Lamont, 2011). A "semi-continuous scoop" sampling method was developed to sample interfluves areas and eventually into the Kalahari sandveld. The gold pan was abandoned as a concentrating tool and a gravitating screen, commonly used by diamond diggers, was introduced to concentrate soil samples between $2 \mathrm{~mm}$ and $0.5 \mathrm{~mm}$ in size. This new method of soil sampling and concentrating of soil samples ultimately led to the discovery of the Orapa kimberlite field (Lamont, 2011). After the discovery of Orapa in 1967, diamond prospecting in Botswana extended progressively deeper into the Kalahari sandveld. The activity of termites to transport material through bioturbation from depth to surface was recognised as a key component in soil sampling for kimberlite indicators in areas where there was significant sand cover (Lamont, 2011). After the discovery of Jwaneng in 1973 it was observed that termite structures extended to a depth of at least 70 metres below surface (Lock, 1985). The indicator counts at surface of kimberlite discoveries after Jwaneng (e.g. Lerala and KX36) were low counts, scarcely above background (Rogers et al, 2013).

\section{Termites}

It is essential to have an in depth understanding of the transport mechanism of kimberlite indicators from the kimberlite to the present day surface of the Kalahari Formation which is via termite bioturbation. Termites require moisture for their saliva as well as for their fungi farms. The termites obtain their required moisture from the water table. In order to access the water table the termites have to excavate access paths from their nests. When termites encounter a kimberlite at or above the water table interface, fragments of kimberlite and indicator minerals resistant to weathering are occasionally transported to surface where they are included in exploration soil samples. While indicators may be included in the construction of termite nests, the majority of the indicators are discarded at vent holes, some distance from the nests.

The concentration of indicators at surface is dependent on a number of factors, some of which are directly dependent on the physical characteristics and capabilities as well as behavioural patterns of the particular termite species dominant in the exploration area. While termites have been recorded to 
access kimberlites to depths of at least 70 metres and possibly deeper than 80 metres, several species found in Botswana are limited to shallower depth penetration. The size of the mandibles of specific species also has a significant effect on the size of the indicators found at surface. Mandibles of termite species in Botswana vary from $3 \mathrm{~mm}$ to $0.5 \mathrm{~mm}$ in size which in turn have definitive restrictions on the size of indicators to be transported to surface (Figure 1, (Uys, 2002)).

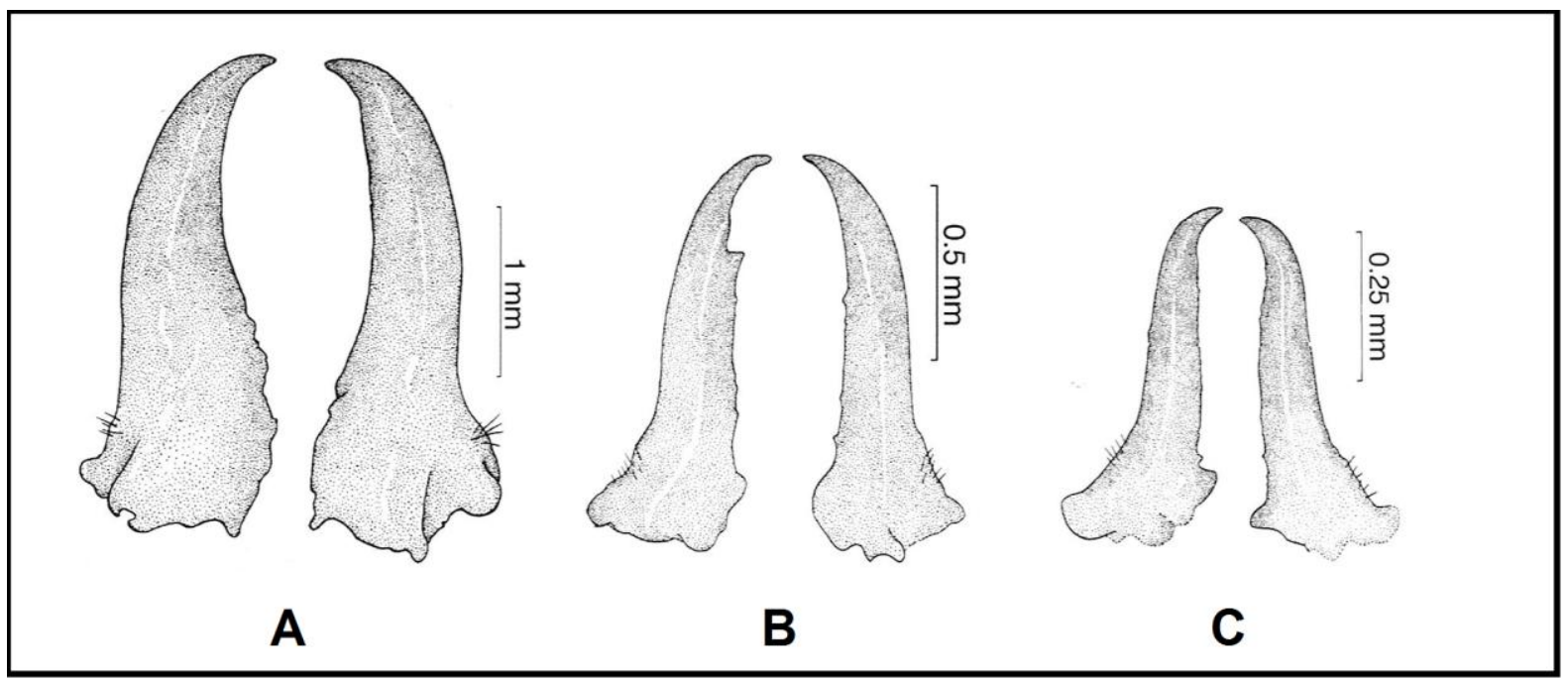

Figure 1: Soldier mandible sizes of (A) Macrotermes natalensis, (B) Odontotermes latericius and Microtermes havilandi (After Uys, 2002).

Several species may be active within an area and up to four species may colonise the same nest (Uys, 2002). A survey conducted in southeastern Botswana found six species of termites active within an area of 0.8 hectare (Dangerfield et al. (1992). Some species build their nest structures above the ground, e.g the iconic nests of Macrotermes michaelseni while others construct their nests underground, e.g. Odontotermes latericius (Dangerfield et al., 1992, Uys, 2002). Darlington (1982) recorded passage densities as high as $1.9 \mathrm{~m}$ of passage and 21.4 storage pits per sqaure metre in the main foraging zone of Macrotermes michaelseni termites, which is $10-35 \mathrm{~m}$ from a single nest. The estimated total length of passages was just under 6000 metres and 72,000 storage pits within an area of 0.8 hectares. Turner et al (2006) reported as much as $190 \mathrm{~kg}$ of wet soil being added to a single termite nest in one rainy season. The excavated material from the access routes is transported from the water table to surface in a "bucket system", particles being passed from termite to termite. Not all indicators will reach surface as particles are abandoned between the kimberlite and the surface. The transportation of indicators to surface has been an ongoing process throughout the deposition of the Kalahari Formation and continues today. Some species of termites are active all year round, others have seasonal activities associated with the breeding of alates. In general, termite activity is minimal during the dry, winter season.

\section{The Future}

In the absence of kimberlites with distinctive aeromagnetic signatures, the discovery of future diamond mines in Botswana will be closely associated with an in depth understanding of the relationship between indicator size and concentration in surface soils and the seasonal behaviour, depth penetration capabilities, bucket system transport efficiencies and mandible size of the termite species within the exploration area. The size distribution of indicators at surface is closely linked to the mandible size of the dominant species of termite in the area. For example, if the dominant species within the exploration area is one of the eight Microtermes species with a mandible size of $0.5 \mathrm{~mm}$, it is unlikely that a significant number of indicators will be found in excess of $0.5 \mathrm{~mm}$ in diameter. Small indicators $(\sim 0.5 \mathrm{~mm})$ have often been interpreted as "distal from source" and indicative of significant transport from source. Standard screen sizes used in Botswana diamond soil sample programmes $(0.425-2 \mathrm{~mm})$ may not capture sufficient indicators in a Microtermes dominant area to create an 
anomalous concentration. Termites, due to the bucket system of grain transport, will be less efficient in transporting indicators to surface the greater the depth of the Kalahari Formation. It is possible that a significant "anomaly" consists of a single indicator. In the past single indicators have been interpreted as "background". Seasonal activity may have a significant impact on soil sample results. When termites are very active they are likely to bring a greater amount of material to surface, e.g. when they need an increased amount of water during the alate breeding season. Conducting a soil sample progamme during this period of high termite activity may result in sporadic anomalous counts of indicators in a soil sample. Sampling the same area a few months later may result in a completely negative sample. Indicators, due to their higher density $(>3.4 \mathrm{~g} / \mathrm{cc})$ than the quartz grains $(2.7 \mathrm{~g} / \mathrm{cc})$ making up the vast majority component of the Kalahari sand, are likely to sink into the sand profile soon after being discarded at surface by the termites. The distribution of indicators at surface my not be spatially closely associated with the nest, but may be be tens of metres distant if it has been discarded at a vent hole. Volumetrically, far more kimberlite fragments than kimberlite indicator minerals are likely to be excavated by termites and discarded at surface. Trace element sampling analysing for LREE's and HREE's anomalous in kimberlites relative to the intruded sub-Kalahari bedrock may be considered as a follow-up programme when indicators are recovered from soil samples.

In conclusion, areas in Botswana where indicators recovered from soil samples and have been described as distal from source or "background" will require re-evaluation. Without detailed termite studies the rate of discovery will continue to decline. However, a kimberlite exploration programme integrating an in depth knowledge of the dominant termite species in the exploration area with adapted exploration techniques has significant potential to unlock a new wave of discoveries in the sandveld region of Botswana. The magnitude of termites to the future of kimberlite exploration in Botswana should not be underestimated.

\section{References}

Dangerfield, JM, Veenendaal, EM, Riddoch, BJ, Black H (1992) Termites and land use in south-east Botswana: Variety and abundance of termite surface features. Botswana Notes and Records 24:165-179.

Darlington, JPEC (1982) The underground passage and storage pits used in foraging by a nest of the termite Macrotermes michaelseni in Kajiado, Kenya. J Zool 198:237-247.

Lamont, G (2011) The Quest for Diamonds in The Bechuanaland Protectorate and Botswana. In: De Wit, MCJ, Köstlin, EO, Liddle, RS (eds) Prospecting in Africa De Beers Consolidated Mines Limited pp 171-201.

Lock, N (1985) Kimberlite exploration in the Kalahariregion of southern Botswana with emphasis on the Jwaneng kimberlite province. In: Raines GL et al (eds) Prospecting in areas of desert terrain. Institute of Mining and Metallurgy, London, pp183-190.

Rogers, AJ, Hough, TG, Davidson, JM (2013) KX36-rediscovering the diamond exploration potential of the central Kalahari in Botswana. J S Afr Inst Min Metall 113:539-545.

Turner, S, Marais, E, Vinte, M, Mudengi, A, Park, W (2006) Termites, water and soils. Agricola, 16: 40-45.

Uys, V (2002). A guide to the Termite Genera of Southern Africa. Plant Protection Research Institute Handbook No. 15, Agricultural Research Council, Pretoria, pp 116 